\title{
Bogen og tingene
}

\section{John Updike og 60erne}

\author{
HANS HAUGE
}

John Cougar Mellencamp said on an MTV interview that the sixties was a dishonest time. He said, 'We screamed a lot, but really all we did was get stoned. Jon Wiener, Professors, Politics and Pop (1991)

\author{
"I don'f know," Harry demurs: , We \\ put him [Nelson] through same pretty \\ wild scenes back in the late Sixties." \\ John Updike, Rabbit at Rest (1990)
}

\section{Indledning}

Updike har skrevet fire romaner (novels) om eks-basketballspilleren Harry 'Rabbit' Angstrom. De foregår i Brewer (Reading), Pennsylvania. Den første hed Rabbit, Run og udkom i 1960. 'Rabbit'1 er det øgenavn, han har fået på grund af sit udseende („,breadth of white face, the pallor of his blue irises, and a nervous flutter under the brief nose"), men der alluderes også til Beatrix Potters børnebøger om løbende harer. I 1971 kom en fortsættelse, Rabbit Redux, hvor 'redux' betyder vendt tilbage. Fordoblingen af R'et bevares i Rabbit Is Rich og Rabbit at Rest. Rabbit er i den første bog 26, i den næste 36, så 46 og 56. Stort set samme alder som Updike selv. Rabbit blev født i 1933, Updike i 1932. Hvor Rabbit, Run skriver Eisenhower tidens historie, SOerne, er Redux en Nixon-tresserroman, som foregår i 1969.

Af John Updikes prosafiktioner er der en, der skiller sig ud fra de øvrige: Marry Me (1976). Den er nemlig en såkaldt romance, medens alle de andre er novels. 2 Denne forskel mellem romance og novel kan man sprogligt, indholdsmæssigt og genremæssigt fore- 
tage på engelsk. Spændingen mellem de to former har været med til at forlene prosafiktionen i den engelsksprogede verden med en del mere dynamik end i den øvrige verden. Den klassiske amerikanske romans form er romancen, som vi kender den fra Hawthorne og Melville. Mod slutningen af det nittende århundrede kom romancens modsætning, the novel, hos realister, naturalister og 'veritister' som Hamlin Garland, William Dean Howells og Frank Norris. Henry James forsøgte dernæst i sine tekster at ophæve forskellen mellem de to. James' romaner er dermed hverken novels eller romances. Hans modernistiske fiktioner blev senere modeller og dermed vanedannende. Hos ham blev showing sat over telling, og en roman, der viste i stedet for at fortælle, blev regnet som den bedste i æstetisk forstand. Romanen blev dramatisk. Hemingway og Fitzgerald.

Først med Wayne Booths Chicago-moralske teori om romanens retorik blev fortælling (telling) igen rehabiliteret eller ligestillet med showing. Det kunne ikke lade sig gøre, mente Booth, ja, det var måske endda uetisk, at forfatteren forsvandt, som tilfældet var hos Henry James, Hemingway og T.S. Eliot. Han var der jo alligevel implicit et eller andet sted. Booths romanteori falder i tid mere eller mindre sammen med opgøret med den upersonlige teori i poesien; dette opgør markeredes med ankomsten af den konfessionelle poesi, hvis hovedværk må være Robert Lowells Life Studies, (1959). Den forsvundne forfatter vendte tilbage. Hun blev synlig, fordi hun var blevet en hun, og hun skulle være synlig enten som kvinde eller senere som sort. Ralph Ellison var for usynlig, Sylvia Plath var til stede. ${ }^{3}$ Den upersonlige forfatter passede dårligt til 60ernes personlige, bekendende og selvrealiserende stil, skønt forfatterens død blev holdt i live af Thomas Pynchons forsvinden. Pynchon blev i de konfessionelle forfatteres regeringstid næsten den eneste, der repræsenterede den franske forfatters samtidige og i forhold til Amerika forsinkede død. Ikke blot blev forfatteren igen synlig, men også i empirisk forstand forsvunde, oversete og glemte forfattere blev genoplivet. Op til overfladen dukkede i tresserne f.eks. Frederick Douglass' slaveberetning Life and Times. ${ }^{4}, 5$ Den vender tilbage i John Updikes Rabbit Redux fra 1969; endda og tilsyneladende før denne 
tekst (altså Douglass' og ikke Updikes) blev en uundgåelig del af den amerikanske litterære kanon. Et motto fra Douglass' tekst indleder mindre overraskende Rabbit at Rest - Reagan-Bush tidens krønike (1990).6 John Updike begyndte også selv i SOerne som selvbiografisk, synlig forfatter med Pigeon Feathers and Other Stories som på-sporet-efter-den-tabte-tid noveller.

Når jeg har gjort noget ud af at fremhæve forskellen mellem 'romance' og 'novel', da skyldes det flere forhold. Jeg vil læse Updike som realist, som sociolog, historiker, krønikeskriver: altså 'novelist'. Han eksperimenterer ikke med form, alligevel er det intet umoderne eller usamtidigt over ham. Tony Tanner indleder sit afsnit i det uundværlige hovedværk om den nyere amerikanske roman, City of Words, med enne karakteristik:

John Updike seems on first reading to stand quite apart from his contemporary fellow writers. His work reveals no visible need for continually renewed formal experimentation and he seems serenely immune from the paradoxes of the fiction-maker which beset John Barth. For his subject matter he has taken New England suburbia and at a time most. American novelists seem to regard middle class life as a desert of unreality?

Hans æuvre er stort set renset for metafiktion, surfiction og lignende. Han undgår næsten den uvane at skrive om forfattere, der er igang med eller som ikke kan skrive. Kunsten eller romanen tematiseres stort set aldrig.8Men som nævnt har han begået en enkelt 'romance'. Der er sandt at sige visse af hans tidligere romaner, der kunne retfærdiggøre, at man kalder hani en stærk „mythographer", som Frank Kermode har gjort.9 Det giver mening, hvad både The Centaur og Couples angår. At karakterisere ham sådan var tidstypisk, da man derved tilnærmede ham til Joyce og Eliot, idet disse kunne siges at praktisere den 'mytiske metode', som Eliot kaldte det. Den består i, at der bag den realistiske, observerede detalje findes et mytisk mønster. Denne skrivemåde blev parodieret af John Barth i Giles Goat-Boy. Men det er sandt, at der er en del Joyce i Updike, og den Joyce, der er tale om, er forfatteren til Dubliners. 
Den amerikanske roman i 50erne og 60erne, altså i epoken efter de 'store' modernister som Herningway, Fitzgerald, Faulkner, Warren og Steinbeck, blev ikke og kunne næppe beskrives som 'realistisk '10 og næppe heller modernistisk; undertiden blev den beskrevet som en bevidst blanding (fusion) af forskelle genrer og former (modes). Undertiden blev den kaldt post-moderne. Ordet 'fusion' er Ihab Hassans, der i 1962 skrev: ,n naturalism and symbolism, comedy and tragedy, picaresque and romance, even surrealism, crowd the form of the recent novel [...] The fusion of modes in contemporary fiction [...] does not prove that ours is a generation of cool and silent writers. Fusion does not always mean confusion. "11 Richard Kostelanetz, der redigerede den antologi, hvori Hassans essay er at finde, bidrog selv med en oversigt over samtidens prosafiktioner. Han nævner en lang række dengang nye forfattere (dog ikke Updike ${ }^{12}$ ) som Joseph Heller, John Barth, Thomas Pynchon, Donald-Barthelrne (han kalder de tre førstes romaner "absurd novels" med henvisning til tidens drama), Nabokov, Burroughs og Walker Percy; og så summerer han op: „All these novels belong in the great American tradition of non-realistic romance: the novel of man and civilisation (such as Huckleberry Finn) which has always said that human society offers man no salvation, now receives an absurd twist [min understregning]. "13 Updikes romaner er ikke 'fusioner' og, på nær een, ikke 'romancer'.

Ukendt med den amerikanske tradition ville visse vist studse over at se f.eks. William Burroughs ]Jaked Lunch klassificeret som en romance (med en absurd vinkel). Hvor Hassans diagnose fokuserede på det nye: Fusionen af mange traditioner og former, da fremhæver Kostelanetz kontinuiteten mellem den klassiske, amerikanske romance og nutidens (dvs. 50eme og de tidlige tressere). Vi kan i Hassans beskrivelse måske ane begyndelsen til hans senere postmodernistiske fase. For litteraturen efter krigen, den der fulgte den klassiske modernisme, blev allerede dengang karakteriseret som 'post-modem'. Den første til egentlig at bruge termen var den lærde enestående, Harvard professor Harry Levin i 1960 i Canada: ,that anti-intellectual undercurrent which, as it comes to the surface, I would prefer to call post-modern."14 
Levin er forfatter til bogen om 'romance' og 'novel': The Gates of Horn: A Study of Five French Realists. Og så endelig: Harry Levin var John Updikes lærer på Harvard, og Updike har medtaget sin anmeldelse af Levins bog i samlingen Assorted Prose. $1^{5} \mathrm{Jeg}$ kalder ham befriende enestående og vil bruge det samme ord om Updike: De er begge umulige at underordne under en almen betegnelse, som også Tanner antydede. Levin er hverken det ene eller det andet: nykritiker, strukturalist eller historist. Levin har dertil en ultrakort realisme teori, eller måske snarere et svar på gåden: "What is Realism?"16

\section{Mellem romance (ivory) og realisme (honest horn)}

Titlen på Harry Levins værk om realismen ${ }^{17}$ The Gates of Horn henviser til de to porte, som drømme har (Homers Odyseen (XIX, 560-65))_18Den ene kan omskrives til fantasiens eller romancens, den anden til realismens. 60ernes roman stod ved en korsvej eller et dilemma (jvf. David Lodge i The Novelist at the Crossroads) mellem den eksperimenterende, metaforiske romance-modernistiske vej eller den anden mere prøvede vej: den metonymiske, realistiske, 'honest horn'. Levins realismeopfattelse kan, som Updike nævner i sin anmeldelse, sammenfattes i diktumet: „realism presupposes an idealism to be corrected." Updike bemærker, hvordan romanen i sin essens for Levin er realistisk og bundet til borgerligheden, men føjer til, at da er romanen måske ligeså død som eposet og romancen, fordi den sociale entropi ${ }^{1} 9$ har smeltet aristokratiet og bønderne væk, for og det var disse to, der gav ordet 'bourgeois' sin mening. Hvor er vi så nu (1963)? Hvis Levin har ret, må Updike mene, da er der ingen andre steder at gå hen end "towards the gate of ivory. Prose narrative needs to refresh itself at the springs of myth and dream." Han slutter med, at der nu findes forsøg på at "shake off the heavy spell of realism." 20 . Imidlertid passer denne bekendelse til myten, drømmen og det anti-realistiske bedst og kun til den roman, der udkom samme år som anmeldelsen, The Centaur, der er en realistisk roman med en mytisk dybdestruktur. ${ }^{1}$ Denne roman er måske slet ikke typisk for Updike, men det var på en 
eller anden måde mode at iklæde handlingen en mytisk dragt dengang - tresserne var også 'The Age of Frye'. Omkring i midten af 50erne havde Leslie Fiedler slået fast i endnu et trillingsk anti-parringtonsk værk:,, Yet the contemporary American author [i 1955, hh] no longer believes that a work of art can be judged primarily by its accuracy in reproducing ordinary speech or rendering literally the horrors of Chicago slums; for us, the reality, the value, of a work of art lies in its symbolic depth and resonance, not the exhaustiveness of its data." 22 Den Updike, der vandrede mod 'the gates of ivory', blev senere transformeret til den uforbederlige romantiske forfatter Henry Bech (i Bech: $A$ Book). Eilers viljeg mene, at Updike vendte tilbage til eller forblev trofast mod en form for realisme i Levins ånd, hvori en idealisme eller en idealist altid skal korrigeres eller bliver korrigeret. Man skal her se Levins og dermed Updikes værker som en slags modstrømme.

Og Harry 'Rabbit' Angstrom er en amerikansk idealist. Han tror på Amerika og drømmen, utopien; han er en amerikansk Adam, der konstant konfronteres med den amerikanske virkelighed (res). Updike anfører i sin Levin-anmeldelse, at der stadigt findes en konflikt, på hvilken romanen kan basere sig, nemlig den mellem indre og ydre eller mellem anima og res. Denne konflikt anses af og til for at være ærkeamerikansk. I Lionel Trillings berømte opgør med Parrington-traditionen og kritik af Theodore Dreiser hedder det om Parrington: „he expresses the. chronic American belief that there exists an opposition between reality and mind and that ane must enlist oneself in the party of reality. '23

Der var også et andet især amerikansk dilemma for romanen dengang, og det er der endnu stærkere nu. Også dette kan illustreres med de to drømmeporte; for det synes som om filmen dengang og nu repræsenterer elfenbensporten, medens romanen er tvunget gennem den anden port, der fører væk fra $\mathrm{Holl}_{\mathrm{y} \text { w }}$ ood. Det skal forstås sådan, at filmen nok er den største trussel mod romanen. Romanen har da flere muligheder konfronteret med den filmiske udfording; den kan forgæves at søge at efterligne filmen, men da vil den tabe i konkurrencen eller nøjes med at blive 
et filmmanuskript; eller den kan prøve at være et alternativ og ikke blive læst, eller den kan forny sig selv ved hjælp af filmiske teknikker. ${ }^{24}$ Updike har leveret filmmanuskript (The Witches af Eastwick - hvor, som altid, en god bog blev en dårlig film); han har skrevet en roman om film (In the Beauty af the Lilies), men han har også forsøgt at overføre teknikker fra filmen til sine romaner. Det gør han i 'Rabbit'-tetralogien. De er nemlig alle skrevet i noget så sjældent som præsens; det er ganske nyt for romaner, og det giver en ganske særlig læseoplevelse. Updike fortæller selv, at Rabbit, Run havde en slags undertitel: „A Movie"; , ) saw the present tense of the book as corresponding to the present tense in which we experience the cinema."25 Morten Nøjgaard bemærker f.eks. "Så langt tillbage, vi kan følge fiktionen, har de fortællende tekster været karakteriseret ved konsekvent brug af fortidig tempus [...] I nyere tids skriftlige litteratur er meddelsessituationen imidlertid en anden; alligevel er fortid stadig den dominerende fortælletempus." Han forklarer det med, at derved signaleres det, at man står overfor en digterisk fortælling. Han nævner dog også, at der er flere og flere, der er begyndt at bruge grammatisk præsens (uden dog at nævne hvem) for "igen at sætte sproget $i$ stand til at medvirke til dannelsen af værkets tidsdimension."26 Det sker dog især i 1. persons tekster, men Updikes er tredje person.

Rabbit, Run udkom, da det fænomen, der hedder American Studies var på sit højeste. American Studies var en myte- og symbol skole, hvis "powerful temptation" var at "organize the study of the United States in terms of what set it apart from other countries and peoples and cultures. "27 Heri privilegeres næsten altid romancen på bekostningen af romanen (the navel) som det specielt amerikanske. I 1955 udsendte American Studies en af sine kendte klassikere R.W.B Lewis's The American Adam. Skønt bogen beskæftigede sig med det nittende århundrede, var den forsynet med en epilog om den nuværende situation: „Adam as Hero in the Age of Containment." Heri siger Lewis, at "the American as Adam has been replaced by the American as Laocoon; the Emersonian figure - 'the plain old Adam, the simple genuine self' - has been frowned out of existence. "28 Amerika var havnet 
i en fastlåst situation, i en form for håbløshed, som Lewis mente, at erindringen om det nittende århundrede kunne være et inspirerende modbillede til. Der var to defekter, som amerikansk litteratur led af, den ene var fjendtlighed over for naturen og den anden en mistro til erfaringen. Men der var helte for Lewis i det tyvende århundredes litteratur; helte der var i stand til at begynde forfra befriet fra historiens $\mathrm{b}_{\mathrm{y} r}$ de, med tro på, at 'ung må verden (America) endnu være' og med agtelse for naturen. Helte der inkarnerede das Prinzip Hoffnung. Det var Fitzgeralds Gatsby, det var Faulkners Isaac McCaslin (i The Bear); det var Ellisons usynlige mand, Salingers vrede unge teenager og Bellows Augie March. „Bach of them struggle tirelessly, sometimes unwittingly and often absurdly, to realize the full potentialities of the classic figure each represents."29 Updikes Rabbit er endnu figur, vi kan føje til rækken af amerikanske Adamer. En af de første studier af Updikes forfatterskab var Larry E. Taylors Pastoral and Anti-Pastoral Patterns in John Updike's Fiction.30 Den er et typisk eksempel på en American Studies læsning af et amerikansk forfatterskab. Den fulgte samme teknik som John F. Lynen's nylæsning af Robert Frosts forfatterskab.31 Og argumenterede for pastoralen som en særlig amerikansk genre eller modus.32 Taylor læste Rabbit, Run som en anti-pastoral satire, altså en kritik (korrektion) af Harry Rabbit Angstroms pastorale drøm (idealisme). Denne læsning var ment som et alternativ til eksistentialistiske læsninger, der fokuserede på Rabbits svenske efternavn 'Angstrom', der dels henviser til måleenheden (en ti-millardte-del af en meter) og dels til begrebet 'Angst'. Taylor forsøgte også at 'finde' en mytisk dybde bag den realistiske overflade.

Rabbit, Run begynder "Boys are playing basketball". Rabbit Redux "Men emerge", Rabbit Is Rich "Running out of gas", og Rabbit at Rest: ,Standing amid the tan, excited post-Christmas crowd." I alle tilfælde, som nævnt, præsens; tredje person og udvidet tid. I alle tilfælde befinder Rabbit sig i en gruppe, måske et fællesskab, som han dog er udelukket fra. I første eksempel ser han et hold af børn, der spiller det spil, basketball, dette ægte, amerikanske YMCA-boldspil, han selv var en berømt udøver af.33 I det andet eksempel er det en gruppe arbejdere, som han 
heller ikke har meget tilfælles med; i det sidste en mængde (crowd). I det tredje er han, som alene vil overleve oliekrisen. Harry introduceres aldrig alene først, men altid som en mand i mængden. Den første roman slutter med, at Rabbit forlader mængden, samfundet, systemet: „Ah: runs. Runs." Verbet er stadigt præsens, men uden personligt pronomen. Dette ord er det sidste, ganske som det næsten er det første i Finnegans Wakes 'riverrun'. Der er ikke tale om en hel sætning; kun 'runs'. Som flere har bemærket er denne slutning prototypisk amerikansk. Helten, - Adam, ,clears out of the territory". Den arketypiske slutning på den amerikanske roman, som vi kender fra Huck Finn.

Redux slutter: „Sleeps. He. She. Sleeps. O.K.?" Præsens igen, men sætningen underligt klippet op, med fortællerens retoriske spørgsmål. O.K.? Var det? Og endelig Rabbit at Rest: „Maybe. Enough." Måske dør Rabbit, i al fald døde fortællingen om ham. Vi har făet nok. Det første 'runs' inviterer til, at vi spørger: 'hvorhen?' I den næste får vi svaret; han er vendt tilbage (redux) til konen; og bogen slutter med, at det nu er konen, der tager ham tilbage efter at været løbet fra ham. Sådan gjorde koner i 60erne, hvor. den vigtigste revolution var den 'lille franske revolution'34 i soveværelset.

\section{Rabbit i 60erne}

Still, she is showing him what she has, right up to the triangle af underpants, which is ane more benefit af being alive in 1969.

Updike, Rabbit Redux

Rabbits 'pastorale' drøm korrigeres i Rabbit, Run, men han mister ikke drømmen. Han repræsenterer den idealisme, som Levin talte om, og som består i drømmen om det naturlige, det agrare, landet og friheden. Han er stadigt i Rabbit Redux den typiske amerikaner, der drømmer sig tilbage til det ægte, republikanske Amerika. Hvor naturen og landet var forsvundet i den første 
bog, da er det selve det forenede Amerika, der er ved at forsvinde i den anden; unum er ved at blive pluribus. På en enkel og pædagogisk måde illustrerer de to romaner skiftet fra konsensus til konflikt-Amerika; det skifte der arbejdes ud fra hos mange historikere, sociologer og historisk-sociologisk interesserede litterater, skønt der er tale om en kliche. På samme tid opløses American Shidies som ide ${ }^{35}$ og spaltes ud i forskellige dele: Black Studies, Southern Studies, Women's Studies osv. Der sker en regionalisering eller balkansiering. Hvor Rabbit Run kunne læses inden for American Studies paradigmet, der kan man ikke gøre det med fortsættelsen; den afspejler opsplitningen.

Rabbit er republikaner, national og forsvarer Vietnamkrigen; deri består hans quixotisme. Hvor han som 26-årig løb fra konen, er det her i 60erne konen, der emanciperer sig, er kommet ud og arbejde, og som løber fra ham med en græsk-amerikaner. Rabbit er arbejdet, men i et truet erhverv; han er typograf ved Verity Press. Updike har karakte iseret Rabbit sådan:

Like me, he has lived his adult life in the context of the Cold War. He was in the Army, ready to go to Korea, hawkish on Vietnam, proud of the moon shot, and in a sense always justified, at the back of his mind, by a concept of freedom, of America, that took sharpness from contrast with communism. If that contrast is gone, then that's another reason to put him, regretfully, to rest in 199036

Rabbit Redux handler om 60erne: O m sex, race, Vietnamkrig, narkotika, oprør osv.; men den behandler ikke disse emner på 60er maner, såfremt vi altså kan sige, der er en sådan. Der eksperimenteres med sar.nlivsformer og alle andre former $i$ teksten, men teksten eksperimenteres der ikke med. Den omhandler det typiske ved 60erne uden at være typisk for 60erne. Jeg accepterer her af $\varnothing$ konomiske grunde de to karakteristikker af 60ernes litteratur, som Hassan and Kostelanetz leverede: Fusion af forskellige modi og ikke-realistiske, absurdistiske romancer. Ved et symposium på Brown University samledes i 1988 en lang række 60 er romanforfattere for at gøre status. Det var arrangeret af Robert Coover, der karakteriserede dem sådan: „Many of these writers rose to farne, or were at least published, in the 1960s, when 
the most dangerous thing to do was to celebrate the imagination [...] It was a time when we believed that the new times, the new age, changing values recquired new structures, new fiction, changing forms." 37 Det passer nu nok slet ikke, hvad Coover sagde der. Det var vel det mindst farlige at celebrere fantasien, og en af dem, der ikke gjorde det, var Updike, som, for at gentage det, ikke mente nye tider krævede nye strukturer, ny fiktion, ændrede former. For hvem var i 60erne og i Updikes romaner idealisterne, der skulle korrigeres? Hvem var drømmerne, fantasterne, hvem var realisterne? Hvem var Don Quixote og hvem var Sancho Panza?

Rabbits kone, Janice, forlader ham; og han bliver på den måde enlig far for sønnen Nelson, men, hvad der er vigtigt, han bliver i huset; han beholder det. I 60erne begyndte poppsykologer at tale om den faderløse familie - Updike gør det modsatte. På ar: bejdet kommer han i kontakt med en neger, som det altså hed dengang. Via ham indvilger Rabbit i at huse en 18 årig rig middelklasse pige; en drop-out, en hippie, der har forladt sit hjem. Hun flytter ind. De går i seng med hinanden. De ryger forskellige ting. Senere flytter en radikal, sort aktivist Skeeter ind i huset, og de har nogle gevaldige diskussioner. Huset brænder, Jill dør, Skeeter flygter, konen vender tilbage. Bogen slutter i sengen med, at de sover - på et motel.

Det, der flytter ind i huset, der brænder ned, er 'det andet Amerika'; det nye, det subkulturelle, ungdomskulturen, drugs, fri sex, borgerrettighedsbevægelsen, negre. Det er næppe muligt andet end at læse dette allegorisk. „Do I really want to be integra.ted into a burning house?" spurgte Jarnes Baldwin i The Fire Next Time, - er der en skjult hentyding til Baldwin i Updikes brændende hus? Romanen foregår i året for Woodstock, rocken, Ted Kennedys, the Lady-Killers, biluheld på Chappaquiddick (18. juli): altså '69 og ikke uden datidens seksuelle symbolik i det årstal. Sex hos Updike er altid oral. Det er også året for 'the rise of the silent majority' og månelandingen. Romanen begynder den dag Apollo 11 sendes afsted: 9:32, 16. juli. Bogens andet kapitel begynder den dag den lander på månen; 20. juli. 
Rabbit repræsenterer Middle America og the Silent Majorityog denne gives her stemme. Updike er realist, og moralist på den måde, at det. individuelle og det almene forenes. Rabbit er på en gang individ og type. Huset er America; og det brænder. Jill er ungdomsoprøret; hun dør: Janice er den nye udearbejdende husmor; Sk eter er den 'nye neger'; han flygter. Nelson fremtidens søn.38

Engang hvor Rabbit diskuterer Vietnamkrigen med Stavros (Janices elsker), siger hun om ham:

'He's [Rabbit] silent majority,' Janice says, 'but he keeps making noise,' looking at Stavros hopefully, for a return on her quip.39 God, she is dumb, even if her ass has shaped up in middle age. 'He's anormal produet,' Stavros says. 'He's a typical good-hearted imperialist racist. [...] But Rabbit is locked into his intuition that to describe any of America's actions as a 'power play' is to miss the point. America is beyond power, it acts as in a dream, as a face of God. Wherever America is, there is freedom, and wherever America is not, madness rules with chains, darkness strangles millions. Beneath her patient bombers, paradise is possible.40

Der er mange ting på spil i dette citat. Nixon holdt i 1969 en tale til nationen i tv, som et svar på de mange anti-krigs demonstrationer. Det var heri han foreslog en delvis tilbagetrækning af amerikanske styrker, og at vietnameserene selv skulle overtage krigen (Vietnamization). Her henvendte han sig til det tavse flertal: ,that great silent majority of my fellow Americans [... ] Let us be united for peace. Let us also be united against defeat. Because let us understand: North Vietnam cannot defeat or humiliate the United States. Only Americans can do that."4 1 Dette ville også Rabbit kunne sige og tilslutte sig. Rabbit kan også tænke om Janices røv, som han gør. Men det er en anden stemme, der udtaler ordene om 'America is beyond power'; her er tonen og stilen nærmest shakespearesk og i al fald bibelsk. Det er den implicitte forfatterstemme, der kan udtale denne trosbekendelse skærmet af Rabbit. Og kun på denne indirekte måde kunne den udtales i 1969. Her vises ikke kun, her fortælles.

Ind i Mr Middle Americas hus, ${ }^{42}$ ind i det tavse flertals borg, kommer så først hippie-pigen Jill og dernæst Skeeter; den poli- 
tiske korrektheds treenighed: race og gender og class. Men forskellen til nu er, at denne tresserroman handler om politiske korrekte udsagn, men teksten selv er det ikke. Det er forskellen på datidens Updike og nutidens T. Corraghesin Boyle.

Rabbits hus ligger i en forstad, der hedder Perm Villas, og gaden er Vista Crescent; det ligger på hvad der engang var et pastoralt landskab: "a softly sloped valley of red barns and fieldstone farmhouses" (s. 15). Denne beskrivelse er ikke empiri, men drømmen om det forgangne. Jill er den første til at belære Nelson og Rabbit om den nye spiritualitet. Vi hører om hendes syn på Gud, kunsten og universet. Materien er et billede af ånden, siger hun. Men vi kan ikke se og høre universets musik, fordi "our egos make us deaf. Our egos make us blind. Whenever we think about ourselves, it's like putting a piece of dirt in our eye." Sønnen Nelson kan høre ekkoet: ",There's that thing in the Bible." Rabbit er "entranced" over at høre dette; som er en lille æstetisk . etik. I kapitel III er negeren så i huset. ,'Themanis aNegro. 'What the hell,' Rabbit says, standing in the front hall beside the three chi:me tubes. 'Hell, man, it's revolution, right?'" (s. 205) Skeeter og Rabbit fører endeløse diskussioner om race. En dag opdager Rabbit Skeeters bøger: deriblandt, som nævnt, Frederick Douglass' The Life and Times. Efter de mange diskussioner enes de om at læse op om aftenen, og det ender med, at Rabbit læser højt for Skeeter fra Frederick Douglass. Der er en fabelagtig scene, hvor vi læser om Rabbit der læser om en slavepige, der får pisk, og medens det sker, reagerer Skeeter på teksten ved at voldtage Jill. En mimetisk vold bliver virkelig i en anden mimesis (romanen). Der opstår dog en forståelse eller forsoning mellem de tre; mellem det gamle (hvide) Amerika og det nye (sorte) med hippien som scapegoat. Rabbit tog jo disse to til sig, husede dem, der ikke var plads til, var deres næste, på den eneste måde man kan være det - uden at ville det. Men som sagt: Huset brændte, den sorte forsvandt (som Huck Finn), hippien døde, og det hele kunne begynde igen på et Motel. 


\section{Den trykte tekst og tingene}

Updike er detaljens mester og en enkelttingenes digter og vogter. Hver ting registreres, sanses, benævnes og gives stemme med stor nøjagtighed. Intet overses. Han opregner enkeltting som Whitman. På det punkt er Brett Easton Ellis en fortsætter af Updike.43 I svensk litteratur er det Kerstin Ekman, der gør det samme. Det er et led i Updikes nominalistiske, realistiske æstetik; realisme er res.

Ganske som Rabbit ikke befandt sig godt i 60ernes Amerika, befandt den realistiske roman sig det heller ikke. Er der en sammenhæng? Rabbit repræsenterer gamle værdier, ganske som denne romanform. Kunne den roman ikke repræsentere 60erne ligeså godt som Richard Wrights eller Theodore Dreisers havde repræsenteret tidligere epoker? Var den realistiske roman usamtidig som Rabbit selv? E dnu i dag anses realismen for at være konservativ, medens romancen anses for progressiv, fordi den ikke er referentiel, og fordi den (siger den) er selvbevidst.

Det synes, som om der er en dyb solidaritet mellem Rabbit og realismen. Janice, konen, er en Madame Bovary, der drømmer om græske mænd (der dog har problemer med hjertet). Jill lever i en romantisk, nyreligiøs verden, hvor naturen tænker. Skeeter lever i en bogverden; i en imitation i betydningen imitatio af $\mathrm{Du}$ Bois, Malcolm X og Frederick Douglass. Til slut er Rabbit og Janice Redux på et tarveligt motel - det er virkelighed. Rabbit stod vagt ved den ene port, 'honest horn', medens resten gik gennem 'the gates of ivory', drømmeporten, eller 'the gates of Eden'. Er Rabbit i virkeligheden Sancho Panza, medens de andre er Don Quixoter og Emma Bovaryer? Svaret er vel, at det er ubestemmeligt.

Morris Dickstein er lidt hård ved Updike i sit 70er tilbageblik på 60erne - i bogen Gates afEden. ${ }^{44} \mathrm{Han}$ har også en ganske rammende diagnose af romanens status som sådan i samme epoke: "What died in the sixties was not the novel but the mystique of the novel, its critical prestige, its wide and loyal audience, its status as the royal road to cultural success." Så føjer han en note til, hvor han citerer Gore Vidal (1974) med disse ord: „In that far off time the people one met talked about novels and novelists the 
way they now talk of movies and directors." 45 Dickstein ser Updike sammen med Philip Roth som fortsætter af traditionen fra Bernard Mallamud (moralsk allegoriker), James Baldwin, Wil- liam Styron, J.D. Salinger og Jean Stafford. Om Rabbit Redux : „a remarkable Janus-faced sequel [...] in which a brilliant depiction of a confused, pathetic marriage is followed by a wobbly attempt to haul in a topical theme, The Sixties - personified by a young hippie girl and a black militant, and concluding in a great symbolic fire." Dertil kommer endnu et par sigende udtalelser: „The sixties were a moribund period for the realistic novel"; „the electronic media had entirely displaced the printed word" og "there .was little good sociology in sixties novels" og endelig: „The future readers who look to the novels of the sixties to learn about society are sure to go awry. "46

Dette lover ikke godt, hvis.man vil læse Rabbit Redux som en realistisk roman; som en roman i en medietidsalder; som god sociologi. C. Wright Mills havde i The Sodological Imagination erklæret, at kun sociologien, og ikke romanen eller litteraturen, kunne repræsentere moderniteten. Marshall MacLuhan havde erklæret bogen for død. Og det litteraturkritiske establishment havde forladt realismen og dermed tingene" samfundet. Updike er naturligvis ikke dummere, end at han kan se alt det; romanen tematiserer det selv. Den handler om realismens død, om romanens død, om litteraturens marginalisering og forholdet mellem god og dårlig sociologi. Og det er en af historiens ironier, at Rabbit Redux udkommer samme år som Paul de Mans Blindness and Insight.47 Er det en form for blindhed, hvis man overser en mulig sammenhæng mellem sådan to helt forskellige tekster? De Mans bog handler om, hvad han kald.er et "curious pattem."48 Dette mønster, som går igen i alle de Mans tekster, går ud på, at der altid er en diskrepans mellem almene udsagn (om litteratur) og så de konkrete eksempler. Med andre ord handler bogen om (umuligheden af) 'das individuelle Allgemeine". Denne diskrepans spiller en central rolle i Georg Lukacs' realismeteori, som et af kapitlerne er helliget. Romanen, i De Mans parafrase af den unge Lukacs, forbliver rodfæstet $i$ "the particularity of experience." Og dernæst: „The novel originates in the Quixotic tension 
between the world of romance and that of reality. "49 Dette beskriver, hvad der er på færde i Updikes roman. Kan disse individer Jill, Skeeter, Janice, Rabbit-inkarnere det almene? Det synes, som om Updike har bevaret troen på, at det kan lade sig gøre og dette i modsætning til hans samtidige, der forlod partikulariteten for at leve i en romanceverden.

I Harry Levins essay, „.What Is Realism?" fra 1948 fremfører han, at realisme er knyttet til res, til tingene, samt at der er en forbindelse mellem realisme og real estate, altså huse, ejendom, property. Romanen har at gøre med retten til privat ejendomsret, og dermed er der en tæt forbindelse mellem realisme og liberalisme.50 Og USA er jo det realiserede liberale samfund som sådan. Men Levin var i 1948 en smule skeptisk med hensyn til, om realismen havde en fremtid. Også han talte om "the technological obsolescence of the novel". Den var forudsigelig, fordi ,the instinct for imitation is more effectively satisfied by journalism, radio, film, and above all television. Within the abstracted realm now left to the purer arts, it may be that the instinct for harmony - for order, degree, and arrangement - will prevail again."51 Som det fremgår synes der at have været enighed om, og det gælder i hele epoken fra slutningen af Anden Verdenskrig og til langt op i tresserne, at romanen måtte ændre sig i retning af harmonia, orden, myte, romance eller $\mathrm{li}_{\mathrm{g} n}$ ende, fordi massemedierne havde vundet $\mathrm{i}$ kampen om både det virkelige og imitationen. Updike valgte denne anden vej i begyndelsen, som jeg har nævnt, men fastholder i Rabbit-bøgerne troen på, at den kritiskrealistiske roman kan være sociologi, kan gengive erfaringens partikularitet, kan lade det individuelle repræsentere det almene. I en lidt forenklet sprogbrug sker dette på indholdsplanet. Romanen handler om disse ting.

Derudover iscenesætter den på et andet plan kampen mellem romanen og medierne. Vi har med andre ord at gøre med en roman, der er bevidst om sin, ja, endog flirter med sin 'teknologiske forældelse' og med romanen som truet medium qua 'printed word'. Vi har at gøre med en roman, der ikke er en 'text', men en trykt bog, bogtryk. Rabbit Redux er en af de få romaner, der handler om typografi, typografer, trykning både i henseende til 
substansform og indholdsform. Rabbit er jo ikke tilfældigt typograf; og typografens og typografiens ${ }^{52}$ død falder sammen med den realistiske romans. Ting og huse er ligeså vigtig i denne realistiske roman som mennesker. Og dertil kommer, at mange forskellige medier taler med eller er repræsenteret i romanen. Fjernsynet er tændt i hele bogen og kører konstant i baggrunden; dets stemme er lige så vigtig som personernes. En scene handler om, at Janice, Rabbit og Nelson er på vej i biografen for at see Stanley Kubricks 2001 Space Odyssee: (, The kid liked it, I don't know, it didn't make much sense tome." (s. 58)). Rabbit er, som nævnt, typograf ansat ved Verity Press, og de trykker avisen The Brewer Vat. Uddrag fra denne avis citeres i teksten og er sat med andre typer, end bogen er. Den er en lokalavis, der handler om bysladder. Avisen truer og er truet. Dens ejere truer med at flytte fra det gammeldags trykkeri til et moderne offset trykkeri i Philadelphia. Avisen er truet: „And the Vat might fold up any week. It is certainly a superfluous newspaper (s. 28)." Den historie, der fortælles i romanen om den bortløbne neger og hippiepigen og Rabbits hus, der brænder fortælles også i avisen. Vi læser i avisen om det, der foregår i romanen. Det ene forældede medium (avisen) findes i det andet forældede medium (romanen) trykt med en forældet typografisk teknik af en af de sidste, der kan det håndværk. Vi er med, når Rabbit soetter tekster og hans trykfejl gengives, så vi på et tidspunkt får en sætning som denne: „etaoinshrdlucmfwqvbqjet"(s.191). Og side om side med de gamle medier høres de 'nye' medier: radio, film, fjernsyn, der beretter om verden udenfor; den store verden - universet.53

Tidligere ville det have været en avantgarde teknik, collage eller montage, at indsætte klip fra det moderne massemedium, avisen, i en litterær tekst. Man kan tænke på William Carlos Williams' Paterson eller på kubistiske malerier. I denne bog bliver tekstuddragene fra lokalavisen snarere til gravskrifter. Måske kunne man endda anskue selve romanen, som bog, som medium, som et gravskrift forstået helt materielt. Og jeg mener ikke blot en tilfældig udgave af den, men den udgave, som jeg benytter. 
Romanen er i fire dele og del rv, den sidste, begynder med, at "Rabbit is at his machine (s. 339)." Han sætter historien om, at hans hus brænder, Jill omkommer, og Skeeter flygter. Midt i sætningen prikkes han på skulderen, så han ikke fuldender den. Formanden fortæller ham, at trykkeriet skal gå over til offset. Rabbit ved, hvad det betyder: „So no linotypers, huh?" Og lidt senere "O.K." Og så ,;'ll survive." Bogens allersidste side, altså uden for eller efter bogen, indeholder en note "on the Type": „The text of this book was set on the Linotype in Janson, a recutting made direet from type cas't from matrices long thought to have been made bythe DutchmanAntonJanson [...]". Rabbit Redux er trykt med Janson: „the distinguished seventeenth century old style face"; 54 den er ikke en offset bog. Den er den sidste linotypebog; helt bogstaveligt. Den er et stykke håndværk med dettes aura: "In Linotype, the produet is an actual line of type, called 'slug' in printer's parlance. This is produced by one machine, from matrices assembled through finger action on a keyboard."55 At læse bogen er som at høre jazz på en lakplade; der er i den bevaret ikke blot en form, men en trykkeform der endnu kan sanses, såfremt man ser på bogstaverne og nyder opsætningens æstetik. At holde Rabbit Redux i hånden er som at holde den sidste trykte tresserroman i hånden.

Rabbit fyres, linotype erstattes med offset, bogen taber til fjernsynet og romanen til filmen, ${ }^{5} 6$ realismen til romancen. Hvem vil overleve? O.K.? 


\section{Noter.}

1. Verbet 'to rabbit' betyder 'løbe hurtigt.'

2. Den blev skrevet medens John Updike selv havde en romance; han var ved at blive skilt fra sin første kone. John Updike er måske mest kendt som short-story writer. Flere af hans romaner udkomm_er først i små dele netop som noveller. Updike er dertil også lyriker.

3. Man kunne ikke have kvindelitteratur, hvis forfatteren er død. Eller også er kvindelitteratur og afro-amerikansk litteratur udtryk for den hvide mandlige europæiske forfatters $\mathrm{d} ø \mathrm{~d}$ - den såkaldte DWEM (dead white European male). Updike er måske den sidste WASP-forfatter.

4. Den er nu så kanoniseret, at den findes i sin helhed i nye udgaver af den amerikanske Norton antologi. Douglass er med i Harold Blooms 'lange' kanon i The Western Canon, som også medtager en af Updikes romaner, The Witches of Eastwick.

5, Dette er Douglass' tredje bog, den første og mest kendte er The Narrative of Frederick Douglass (1845). Nævnes ikke i B. Wendells Literary History of America (1905), eller i R. Spillers (1947)- , and yet so unavoidable a text in a literary history of the 1980s." Skriver Werner B. Sollors i "A Critique of Pure Pluralism" (i S. Bercovitch (red.), Reconstructing American Literary History (Harvard, 1986)). Mottoet til Rabbit at Rest fra Douglass citeres i Rabbit Redux.

6. Præsidenters epoker spiller ofte en stor rolle for amerikanere og visse forfattere - måske mere end årtier. Updikes Couples er en Kennedyroman, og i hans Memoirs of the Ford Administration siger titlen alt.

7. Tony Tanner, City of Words (New York, 1971), s. 273. Det er værd at notere sig de mange 'seems', der inviterer til, at der bag overfladen skjuler sig det, der er tydeligt hos de andre. Det mener jeg ikke, der er grund til at antage. Jeg skal vende tilbage til ideen om den af Tanner omtalte 'unreality'.

8. Jeg er nødt til at tage visse forbehold. F.eks. er hans Bech: A Book en - slags undtagelse. Den handler om en forfatter. Visse af novellerne behandler kunstnertemaet.

9. Frank Kermode, Modern Essays (London, 1971), s. 295.

10. Eller symbolsk-realistisk som Hemingway.

11. Ihab. H. Hassan, „The Character of Post-War Fiction in America", først trykt i English Journal. Her citeret efter On Contemporary Literature, red.-af Richard Kostelantz (New York, 1969), s. 37. Hassan forsøgte i artiklen at forsvare samtidens romaner, idet mange så tilbage til de 'store', som jeg nævner. 
12. Updike havde på dette tidspunkt endnu ikke rigtigt gjort sig gældende.

13. Richard Kostelanetz, „American Fiction of the Sixties", i op.cit., s. 643.

14. Harry Levin, Refractions (New York, 1966), s. 271.

15. John Updike, Assorted Prose (Harmondsworh, 1962); „Honest Horn" er titlen; anmeldelsen er ganske kritisk over for Levin og over for realismen!

16. Harry Levin, Contexts of Criticism (New York, 1963).

17. Kun Erich Auerbachs Mimesis kommer op på siden af Levins værk, når talen er om realismeteori.

18. „Drømme har jo to forskellige porte. Den ene er bygget af horn, den anden af elfenben. De drømme der kommer gennem elfensbensporten er blændværk (illusioner) og bedrag (fantasier), men de drømme, der kommer gennem hornporten, går i opfyldelse."

19. Ordet eller begrebet 'entropi' syntes at spille en ganske stor rolle på den tid. Vi kender det også fra Pynchons berømte novelle, det indgår centralt i Tony Tanners City of Words.

20. En af Margaret Drabbles sidste romaner har titlen Gates of Ivory; måske en ironisk kommentar til søster A.S. Byatt. Drabble er ellers 'honest horn'.

21. Updike satte selv stor pris på denne roman, men Charles Thomas Samuels' bedømmelse af romanen kan jeg tilslutte mig. Den ${ }_{I I}$ verges on obscurity", siger han og føjer til: „The obscurity is caused by Updike's decision to wrap his childhood memories in the august mantle of myth." John Updike (Minneapolis, 1969), s. 17.

22. Leslie Fiedler, ${ }_{11}$ A dolescence and Maturity", i Oldsey og Lewis (red.), Visions and Revisions in Modern American Literary Criticism (New York, 1962), s. 255. Fiedler tror, at det var ham, der først talte om postmodernisme, men det var altså Levin.

23. Lionel Trilling, The Liberal Imagination (London, 1961), s. 10.

24. Som hos Robbe-Grillet.

25. John Updike, , ,A Window on Four Decades: The Raobit Novels", The New York Times Book Review (1990). Updike nævner, at en af de få romaner, der også fortælles i præsens er Joyce Carys Mister Johnson. Jeg har ikke undersøgt feltet, men en tilfældig søgning i forhåndenværende romaner viste, at Astrid Saalbachs Fjendens land samt Vasco Pratolonis Cronache di poveri amanti også ofte benytter præsens og tredje person. Det samme gør i perioder Ondaatje i The English Patient.

26. Morten Nøjgaard, Det littercere vøerk (Odense, 1993), s. 165. Nøjaards eneste eksempel er Camus' Den fremmede. Han nævner også dokumentarromanen. 
27. Giles Gunn, The Culture of Criticism and the Criticism of Culture (New York, 1987), s. 151. American Studies skulle være for USA, hvad mandsme-leninismen var for Sovjet.

28. R.W.B. Lewis, The American Adam (1955) (Chicago, 1975), s. 195.

29. Ibid., s. 198.

30. (Carbondale, 1971).

31. John F. Lynen, The Pastoral Art of Robert Frost (New Haven, 1960).

32. „The pastoral tradition implies a conflict between the sophisticated world of the author (or character in prose fiction) finds himself in, and the 'natural', unsophisticated world he longs for." Taylor, s. 5.

33. Rabbit er ligesom Tom Buchanan i The Great Gatsby en tidligere sportsstjerne, der skal finde sig tilrette i en ny tilværelse.

34. Udtrykket stammer fra den tyske sociolog, Ulrich Beck.

35. Der findes af navn, men ikke gavn, endnu American Studies programmer; endda i Danmark, hvor de blev oprettet, da ideen med dem var død. Nu betegner American Studies blot Anything Goes Studies blot det har noget med USA at gøre.

36. John Updike, „The Rabbit Novels", op.cit.

37. „Nothing but Darkness and Talk?" Writers' Symposium on Traditional Values and Iconoclastic Fiction." Critique, vol. 31, nr. 4 (1990). I panelet sad bl.a. John Hawkes, Donald Barthelme, Stanley Elkin, William Gaddis. Alle, så vidt jeg ved, professorer i engelsk ved universiteter. Det er Updike ikke. Måske kunne man kalde hans brug af grammatiske præsens et eksperiment.

38. Han får i den sidste roman et narkoproblem.

39. 'quip' er en smart, sarkastisk bemærkning.

40. John Updike, Rabbit Redux (New York, 1971), s. 47. Dette er originaludgaven, og der en bestemt pointe deri, for den kan kun læses i denne udgave (se nedenfor).

41. Citeret i William Manchesters, The Glory and the Dream: A Narrative History of America (New York, 1975), s. 1165. Gallup rapporterede, at 77 procent af befolkningen støttede præsidenten.

42. Dette hus er Amerika, ligesom Howards End hos Forster er England.

43. Ellis' Less Than Zero er den eneste roman, som Updike bruger som kilde i sin seneste roman, In the Beauty of the Lilies.

44. Morris Dickstein, Gates of Eden: American Culture in the Sixties (New York, 1977),

45. op.cit., s. 92. Dette gælder endnu mere den dag i dag, hvor samtaleemnet er film, fordi der er for megen litteratur. Film har nemlig en kanon.

46. op. cit., 91-93.

47. Dekonstruktion som fænomen og mode dukker først op i romanen Memoirs of the Ford Administration.

48. Paul de Man, Blindness and Insight (New York, 1971), s. ix 
49. Ibid., s. 55. Man skal erindre, at Harry Levin og Paul de Man en overgang var kollegaer på Harvard. Se Lindsay Waters ,Introduction" i Paul de Man, Critical Writings (Minneapolis, 1989). Citatet kunne næsten komme fra Levin.

50. Det siger jeg, selvom jeg er klar over Victor Hugos berømte identifikation mellem romantik og liberalisme (romantikken er liberalisme i litteraturen). Den nye interesse for realisme i litteraturen kan ikke adskilles fra nutidens gentænkning af liberalismen. En frafalden liberalist som John Gray mener ikke, at det postmoderne og liberalismen kan forenes. 51. Harry Levin, "W hat Is Realism?" i Contexts of Criticism (New York, 1963), s. 74. Levin arbejder med Aristoteles' begrebspar fra Poetikken: mimesis og harmonia.

52. Med computeren kan enhver ved et tryk på en knap fremstille snart sagt alle skrifttyper.

53. Hippiepigen taler om universet, drengen Nelson er optaget af rummet (2001); romanen omgives af raketter, russiske og amerikanske.

54. Citeret efter Paul A. Bennett (red.) Books and Printing (New York, 1951). Denne bog om trykning er sat med Jason. Denne, min, tekst vil ikke være en linotype/janson. Mine citater fra Updikes bog vil ikke være citater fra originalen, men vil være ændrede.

55. Ibid., s. 404.

56. Updike i Salon (taget fra Internettet): "Why read?- novel when in two hours you can just go passively sit and be dazzled and amazed and terrified?" 